\title{
Reactions to international health care rankings
}

\author{
Cite as: CMAJ 2017 August 8;189:E1027. doi: 10.1503/cmaj.1095463
}

Posted on cmajnews.com on July 18, 2017.

$\mathrm{n}$ a comparison of health care system performance in 11 high-income countries, Canada was one of three nations ranked below average. Canada ranked ahead of only France and the United States, which took the bottom position. The United Kingdom received the highest rating in the international comparison, conducted by the Commonwealth Fund, a US think tank.

Canada ranked lasted in accessibility and performed poorly in health outcomes and equity. The only two areas in which Canada did not rank near the bottom were care process and administrative efficiency. The poor score on access comes as no surprise, since "waiting is a hallmark of our health system, from primary care to long-term care," columnist André Picard noted in The Globe and Mail. The dismal performance in equity, however, was the "most shocking metric," according to Picard, who added that the report is a reminder that Canada's concept of universal health care is outdated.

On Twitter, federal Health Minister Dr. Jane Philpott referenced the report's findings by stating Canada was "moving up the rank, one step at a time," while acknowledging that there is much more work to do.

In the United States, where President Donald Trump has been attempting to replace the Affordable Care Act introduced by Barack Obama, the health system fared poorly on access, health outcomes, equity and affordabil-

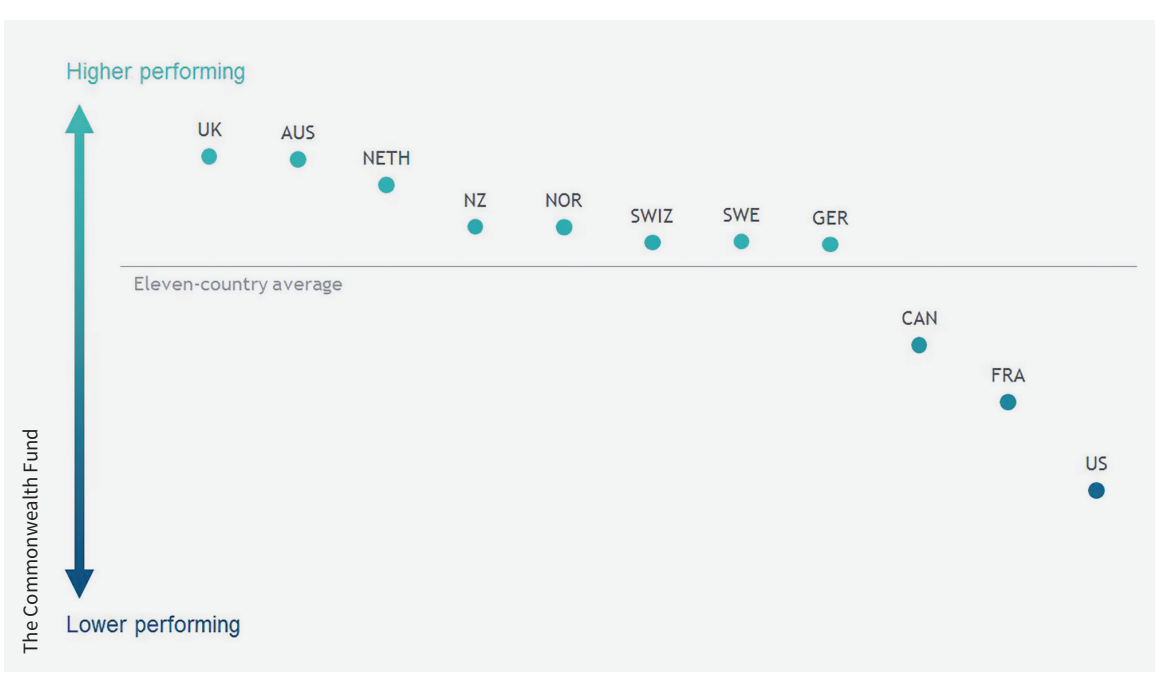

Canada ranked third-last in international comparison of health systems.

ity. According to experts at the Commonwealth Fund, America's health system would improve if more people had health insurance, access to primary care was increased, and the insurance system was streamlined. According to The Atlantic magazine, the Republican party's "Obamacare replacement proposals aren't the way to fix" the problems highlighted in the Commonwealth Fund's report.

The UK's National Health Service, by contrast, was found to have excellent performance in areas such as safety, affordability and efficiency. This comes despite the NHS "being in the grip of the tightest financial squeeze in its history," noted BBC News. When it comes to health outcomes, however, the UK did not perform nearly as well. "If our health service wasn't so useless at keeping people alive, it would have been a clean sweep," a commentator wrote in The Spectator, cautioning Britons not to read too much into the report.

Australia came in second place overall, and ranked number one in both administrative efficiency and health outcomes. Health commentators in Australia noted, however, that the country did poorly in term of equity. As one physician told The Sydney Morning Herald, "I am always surprised and humbled to see how treatment outcomes for patients who have the same disease but belong to different postcodes can be so vastly different."

Roger Collier, CMAJ 